\title{
A saúde dos imigrantes em Portugal
}

Paulo Estrela*

\section{RESUMO}

Objectivo: Este artigo propõe-se apresentar os principais problemas de saúde de populações culturalmente distintas em Portugal: trabalhadores imigrantes e as suas famílias, no contexto da prestação de cuidados de saúde.

Métodos: Foi consultada literatura de referência e artigos na Medline e Google, para além de um trabalho efectuado pelo autor, referentes aos problemas de saúde dos imigrantes, bem como ao modo como acedem e utilizam os serviços de saúde. A pesquisa incidiu sobre artigos publicados nos últimos oito anos em língua inglesa, francesa, espanhola e portuguesa.

Conclusões: A evidência mostra que os imigrantes, frequentemente, têm grande dificuldade em aceder e usar os serviços de saúde disponíveis, o que os torna num grupo de risco acrescido. Revela, igualmente, que os problemas de saúde, na população imigrante, resultam de condições físicas, psicológicas e, talvez mais importante que as anteriores, de condições sociais, que potenciam o risco de adoecer.

Prestar cuidados à população imigrante pressupõe, não apenas reduzir os factores de risco e tratar a doença, mas, igualmente, promover o suporte social necessário tanto a estes doentes como às suas famílias, de modo a que, efectivamente, se consigam eliminar as disparidades encontradas quando se comparam os cuidados de saúde prestados a estas populações com os dispensados à população autóctone. Deste modo, a melhor estratégia será a combinação de medidas que permitam, não apenas reduzir as consequências da estigmatização e exclusão sociais desta população, fornecendo informação sobre as suas caraterísticas culturais, as suas crenças e os seus valores, mas também a detecção e tratamento precoce dos seus problemas de saúde e a promoção da educação para a saúde, através de programas que estimulem a aquisição de estilos de vida saudáveis, especialmente nos grupos etários mais jovens. Da mesma forma, a utilização de intérpretes, ou de mediadores culturais, servirá para ultrapassar as barreiras linguísticas, permitindo uma melhor comunicação e relação entre médico e doente. Por fim, em virtude do desconhecimento, pelos profissionais de saúde, dos padrões culturais e das necessidades específicas destas populações, torna-se necessário que os médicos de família sejam sujeitos a um treino específico que os sensibilize para as diferenças culturais, para ultrapassarem estereótipos e obterem informação e competências na comunicação intercultural, que se reflictam na qualidade de cuidados prestados a esta população.

Palavras-Chave: Imigrantes; Cuidados de Saúde; Problemas de Saúde.

\section{INTRODUÇÃO}

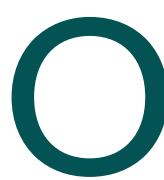

aumento da presença de imigrantes, em território português, conduziu a um contacto mais frequente dos profissionais de saúde com estas populações, culturalmente distintas, e que apresentam expectativas diferentes em relação à prestação de cuidados de saúde. Esta situação deu origem a problemas que, até então, nunca se tinham verificado, para o que muito contribuiu o modo como está organizado o sistema de saúde português, bem como o desconhecimento dos aspectos culturais e as representações sociais estereotipadas asso-

*Chefe de serviço de Medicina Geral e Familiar, Centro de Saúde de Loures ciadas a estes grupos, podendo condicionar, nos profissionais de saúde, atitudes e comportamentos desajustados em relação a estes indivíduos.

Por outro lado, o acto de imigrar constitui, só por si, um fenómeno gerador de grande stress. O que coloca, desde logo, os imigrantes e suas famílias em situação de vulnerabilidade acrescida quando comparados com outros sectores da sociedade. Esta condição tenderá a agravar-se ao longo do tempo de permanência, no país receptor, já que irão ser sujeitos a condições de vida que potenciam o risco de adoecer, tornando-os utilizadores potenciais, ou regulares, do Serviço Nacional de Saúde português.

Neste artigo pretende-se apresentar as principais di- 
ficuldades, vividas por estes grupos, no acesso a cuidados de saúde, bem como os principais problemas de saúde com que se confrontam.

\section{UTILIZAÇÃO DOS SERVIÇOS DE SAÚDE PELA POPULAÇÃO IMIGRANTE}

De um modo geral, os imigrantes têm problemas de saúde e necessitam de cuidados como todos os indivíduos, mas a evidência mostra que, frequentemente, estes indivíduos têm grande dificuldade em aceder e usar os serviços de saúde disponíveis, o que os torna num grupo de risco acrescido.

No entanto, dado que, em Portugal, são escassos os trabalhos científicos que abordem este tema, este aspecto não é completamente conhecido. Aliás, para que se possam delinear estratégias adequadas de intervenção em saúde nestas populações, será necessário que se proceda a estudos de base populacional que identifiquem, para além dos principais problemas de saúde, os determinantes do seu estado de saúde e as formas de responder às suas necessidades. ${ }^{1}$

Recorrendo, igualmente, à literatura internacional, encontram-se vários factores que concorrem para o modo como os imigrantes se servem dos serviços de saúde disponíveis, condicionando, pela negativa, a sua utilização ${ }^{2,3,4}$ (Quadro I).

No caso específico da clandestinidade, só lhes é per-

QUADRO I. Factores que dificultam a utilização dos serviços de saúde pelos imigrantes

- Desconhecimento das formalidades burocráticas (por falta de informação)

- Dificuldade na compreensão/utilização da língua do país anfitrião (para ultrapassar as formalidades administrativas)

- Ausência de indivíduos com competências na área da língua materna destas populações para servirem de mediadores (para melhorar a comunicação com os técnicos de saúde)

- Falta de hábitos de utilização de serviços de saúde (porque inexistentes, escassos ou de má qualidade no país de origem)

- Estabelecimento de uma má relação interpessoal com os profissionais de saúde (por dificuldades de comunicação)

- Situação de clandestinidade (por temor de ser denunciado) mitido acederem aos serviços em situação de urgência/emergência ou em casos específicos: vacinação, vigilância de saúde infantil e de saúde materna e tratamento de doenças infecciosas que constituam perigo para a saúde pública. $\mathrm{O}$ acesso é, sobretudo, mais difícil, no seguimento posterior à resolução das situações mais urgentes. ${ }^{2}$

Contudo, os comportamentos perante os serviços de saúde dependem, igualmente, de factores que podem favorecer a sua utilização, permitindo-lhes adquirir as competências necessárias para ultrapassar as dificuldades com que se podem deparar ${ }^{3}$ (Quadro II).

Nalguns casos, os imigrantes recorrem a familiares ou amigos bilingues. No entanto, podem surgir constrangimentos, tanto no doente como em quem lhe serve de intérprete, ou ser, mesmo, contraproducente, devido às relações de poder que estão geralmente presentes. O mesmo pode acontecer por interpretação deficiente do que lhes foi transmitido, resultante de confusões linguísticas ou das próprias opiniões do intérprete, fruto das suas crenças e representações de saúde e do desconhecimento das características da medicina ocidental. ${ }^{2,5}$

No caso dos imigrantes oriundos dos países europeus extra-comunitários, que possuem níveis de literacia suficientes para utilizarem os recursos de saúde existentes, são a falta de domínio da língua portuguesa, bem como a condição de clandestino (em que muitos se encontram), que condicionam a utilização dos serviços apenas em situação de urgência. Nas restantes situações, recorrem à Farmácia ou a outros imigrantes que sabem ter formação na área da saúde (adquirida nos seus países de origem), estejam eles autorizados, ou não, a exercer a sua profissão em Portugal. ${ }^{2,6}$

QUADRO II. Factores que favorecem a utilização dos serviços de saúde pelos imigrantes

- Elevado nível de escolaridade/qualificação profissional

- Elevado estatuto socioeconómico

- Posição geográfica do país de origem

- Existência de relações históricas entre os países de origem e de acolhimento

- Tempo de permanência mais elevado no país anfitrião

- Maior grau de integração no país receptor 
À medida que a permanência no país se prolonga no tempo, ou obtêm a legalização, todas as comunidades, independentemente da sua origem étnica, se tornam mais utilizadoras dos serviços de saúde. ${ }^{2,5}$ Porém, perante uma situação de doença mais arrastada ou de causa indefinida, recorrem aos serviços de saúde no seu país de origem, devido ao maior conhecimento que detêm sobre o seu modo de funcionamento ou à maior confiança que depositam nos seus profissionais, ou porque os serviços de saúde são gratuitos. Outros ainda, como os originários do sub-continente indiano mas também alguns africanos, procuram os serviços de saúde de outros países comunitários (geralmente Reino Unido, França, Holanda, Alemanha), alojando-se em casa de familiares.

Pelo facto dos primeiros imigrantes a chegarem ao país provirem dos antigos territórios ultramarinos, estabelecendo níveis de comunicação razoáveis com as comunidades autóctones, não se tinha feito sentir a necessidade de implementar as medidas necessárias à aquisição de um nível aceitável de competências linguísticas, não apenas às crianças e jovens destas populações mas, de igual forma, aos adultos. ${ }^{7}$

Mas a posterior entrada, em Portugal, de imigrantes provenientes de regiões onde não se fala português determinou a necessidade premente de se ensinar a língua portuguesa a estes indivíduos, de modo a poderem ultrapassar este obstáculo na comunicação interpessoal e a promover a sua participação efectiva na sociedade.

Porque os profissionais de saúde, em Portugal, não possuem formação específica na área da multiculturalidade, tendem a responder de forma inadequada às situações que se lhes deparam, decorrentes da heterogeneidade na composição cultural e étnica das populações a que prestam cuidados., ${ }^{4,5}$

Para uma actuação apropriada a estas características, necessitariam de aprender a integrar os factores culturais na definição dos estados de saúde e de doença, já que estes condicionam fortemente as atitudes e os comportamentos dos indivíduos. Os próprios comportamentos adoptados pelos indivíduos como resposta à sensação de doença, (sickness ou sick-role dos autores anglo-saxónicos) são condicionados, de modo muito significativo, pelos seus contextos socioculturais. Assim, a actuação com base num modelo bio-psi- co-socio-cultural permitir-lhes-ia perceber a importância do contexto sociocultural na interpretação que cada indivíduo tem da doença, nas expectativas que tem em relação à actuação dos serviços e dos profissionais de saúde e no modo como acede aos cuidados de saúde. Os profissionais dos Cuidados de Saúde Primários, pela globalidade e continuidade dos cuidados que prestam e pela maior proximidade em relação às populações, são os que reúnem melhores condições para implementar este modelo de actuação, já que se poderão aperceber mais facilmente das interacções complexas existentes entre os componentes físico, psicológico e social da doença e da importância que os aspectos culturais têm nas atitudes e comportamentos dos indivíduos, como resposta à sua situação de saúde ou de doença. $^{5}$

\section{PROBLEMAS DE SAÚDE COMUNS NAS COMUNIDADES IMIGRANTES}

\section{Saúde Materna}

Nas sociedades de origem dos imigrantes, sobretudo africanos e asiáticos, o papel da mulher está ainda muito centrado na maternidade e o seu estatuto na família muito dependente da sua capacidade de produzir filhos. Como tal, o início da vida reprodutiva ocorre em idades mais precoces, tornando a gravidez na adolescência uma situação muito comum e tradicionalmente aceite nestas comunidades. ${ }^{2,5}$

Estas gestações em idade precoce, ou avançada (muitas vezes como resultado da reunificação familiar), concorrem para a manutenção de uma maior natalidade nas famílias de imigrantes de primeira e segunda geração, a exemplo do que acontece nos países de origem. Contudo, as profundas transformações sociais a que as mulheres são submetidas, durante a permanência no país de acolhimento, geram novas vulnerabilidades e condicionam o modo e a qualidade dos cuidados que podem prestar aos filhos, pelo que a taxa de natalidade das gerações seguintes, destas comunidades, vai diminuindo, aproximando-se, progressivamente, da das populações autóctones. ${ }^{5,7}$

Devido à idade das gestantes existe um aumento do risco materno-fetal, para o que também contribui o facto de poderem ser portadoras de patologia prévia comum nos seus países de origem, como anemia, malnutrição, hemoglobinopatias, infecções sexualmente 
transmitidas ou parasitoses raras nos países de acolhimento. Para além disto, existe a percepção que estas mulheres solicitam e recebem menos cuidados de saúde durante e após a gravidez. ${ }^{2}$

\section{Saúde da Criança}

Após o nascimento, no que respeita aos cuidados que são dispensados à criança, constata-se que, nas situações em que a coesão do grupo familiar imigrante é fraca ou existe uma rotura evidente com as tradições do país de origem, as referências às práticas tradicionais de educação e de prestação de cuidados às crianças estão muito atenuadas. Se, a isto, acrescer o facto de não terem sido ainda integrados, eficazmente, os aspectos culturais do modelo da sociedade de acolhimento, existe a possibilidade de se gerar uma grande ansiedade e insegurança nos comportamentos das mães, podendo verificar-se que «...um número importante de mães tem dificuldade em encontrar e desempenhar com 'segurança' os gestos necessários a prestar aos seus filhos, divididas entre o saber e hábitos tradicionais de educação, transmitidos no seio das suas famílias, de geração em geração, considerados como 'ultrapassados', e as práticas ditas 'modernas' que lhes são sugeridas ou impostas... quando a mãe se encontra insegura e em conflito quanto aos comportamentos e práticas a adoptar, a ansiedade que daí resulta não deixará de ter influência na sua relação com a criança e no desenvolvimento da sua personalidade» (Ramos, 1990:321). ${ }^{8}$

Nesta situação de vulnerabilidade acrescida, a prestação de cuidados à criança e as práticas educativas passam a ser definidas pelos técnicos de saúde, e pela pressão do modelo cultural da sociedade receptora. Pode ocorrer uma imitação, voluntária e indiscriminada, dos gestos e dos comportamentos sugeridos, como forma de atenuar as diferenças que separam estas mães da população autóctone e promover a sua aceitação, pondo em causa, ou mesmo abandonando, os saberes tradicionais securizantes das gerações anteriores, conduzindo a um conflito intergeracional. A situação será, ainda, mais grave, caso estas mães sejam muito novas, se encontrem sozinhas, não tenham sido iniciadas nas práticas tradicionais da sua comunidade ou não tenham tido ocasião para as treinar, não estejam inseridas num determinado tipo de cultura ou apresentem dificuldade em compreender ou exprimir-se na língua do país de acolhimento. Não dispondo das referências nem da experiência de como cuidar de crianças, não descobrem, em si próprias, recursos para esta função, e também não são capazes de se socorrerem dos apoios institucionais (sociais ou de saúde) do país onde residem..$^{9}$ "São mães deprimidas que abandonam psicologicamente os filhos, desenvolvendo com eles formas de interacção mais pobres, investindo menos na sua saúde, faltando às consultas, não cumprindo os planos de vacinação, o que pode conduzir a graves problemas de saúde, tanto físicos como psicológicos, para estas crianças» (Ramos citada por Soares, 2003:100). ${ }^{5}$

Já nos casos em que as mães foram educadas de forma tradicional, ou iniciadas nas práticas dos cuidados às crianças no seio das suas famílias, ou em contacto com outras mulheres da sua comunidade, assiste-se a uma aliança harmoniosa entre as práticas tradicionais e os comportamentos modernos, adquiridos no país de residência. Geralmente, só os comportamentos exteriores são modificados, mantendo-se os ligados às tradições de origem: práticas mágico-religiosas, postura, gestualidade, memória quinestésica do corpo, que continuam a ser utilizadas dentro de casa. ${ }^{9}$

Mais tarde, sobrecarregadas pelas suas múltiplas tarefas profissionais e domésticas e dispondo de pouco tempo para dedicar aos filhos, acabam por permitir que o convívio familiar seja substituído pela televisão ou pelo meio extra-familiar, passando estes a constituir os referenciais principais no desenvolvimento psico-social das crianças. Esta situação é grave, porquanto se sabe que é a família que representa o espaço sociocultural natural, e de eleição, para a construção da identidade individual e cultural, conferindo-lhe o equilíbrio psicodinâmico de que necessita e deixando traços marcantes no indivíduo para o resto da sua vida. ${ }^{9,10}$

Por outro lado, também o tipo de arranjos familiares nestas comunidades, com um número significativo de famílias reconstruídas ou monoparentais, leva, frequentemente, à deserção do papel parental por um dos progenitores, o que pode condicionar dificuldades económicas, isolamento ou agravamento da situação social do restante agregado, originando graves situações disfuncionais que irão constituir importantes factores de risco na vida futura destas crianças. ${ }^{5}$

Do mesmo modo, o afastamento geográfico entre as várias gerações, impedindo a coabitação ou os contac- 
tos frequentes entre avós e crianças, priva-as do equilíbrio emocional que advém dessa convivência. A presença destes avós significaria, ainda, um enorme apoio para as mães. Ao ajudar a cuidar das crianças e nas tarefas domésticas, permitiria aliviá-las de algumas das suas múltiplas obrigações, ao mesmo tempo que possibilitava a transmissão de práticas culturais e valores tradicionais aos mais novos (que podem estar pouco familiarizados com a cultura de origem da família), facilitando o desenvolvimento do sentimento de continuidade familiar e pertença cultural. ${ }^{2,5}$

Não menos importantes são as condições de vida nos locais onde reside a maioria destas crianças, quase sempre bairros da periferia das grandes cidades ou bairros de génese ilegal. Zonas desordenadas, degradadas e desqualificadas do ponto de vista urbanístico, conduzindo à estigmatização e segregação social e espacial dos seus habitantes, são marcadas por deficientes condições de habitabilidade e de vivência social (falta de conforto, espaço exíguo, sobrepovoamento condicionando promiscuidade e falta de higiene), e graves carências em termos de infra-estruturas e de equipamentos sociais de apoio à população residente. Estas circunstâncias constituem factores adicionais de deterioração da vida das crianças, influindo negativamente na sua saúde..$^{5,9,11}$

Estes cenários urbanos, desequilibrados e desintegradores, que favorecem o estabelecimento de um clima de insegurança e de práticas anti-sociais, ou mesmo de criminalidade, são, frequentemente, os únicos de que estas crianças dispõem para a sua socialização, e onde são submetidas às pressões dos seus pares e a outras influências negativas. Porque são estes os contextos físicos e sociais em que a criança vive o seu quotidiano, vai sentir maiores dificuldades e entraves à sua futura integração e participação na vida pública do país de acolhimento. ${ }^{5,7}$

Para minorar o impacto destas condições adversas, deveriam promover-se políticas de alojamento e de reabilitação urbanística, bem como políticas sociais que ajudassem as famílias, para que as mães pudessem conciliar maternidade e trabalho. Mas estas medidas são difíceis de implementar devido aos enormes custos sociais e económicos que acarretariam, o que a sociedade actual não está na disposição de pagar. «C`est, comme on va voir, l'euro contre l’enfant (...) les traités européens sont malthusiens jusque dans leur rédaction (...) on n`y trouvera rigoureusement rien concernant la démographie, la famille et l’enfant (...) L`Europe s`en désintéresse. Elle ne s`occupe que de la génération présente et de leur bien-être immédiat.» Laulun (2001:13) ${ }^{12}$

Devido às condições apontadas anteriormente, as crianças de algumas comunidades imigrantes têm maior probabilidade de adoecer com gravidade e de necessitarem de internamento hospitalar quando estão doentes, e esse internamento estende-se por um período de tempo superior ao que se verifica nas crianças da mesma idade da população autóctone. Como causas mais habituais são referidas as doenças infecto-contagiosas, as infecções respiratórias e parasitárias e os acidentes domésticos, para além dos problemas nutricionais. $3,4,5$

Vários factores contribuem para a necessidade de actuação em meio hospitalar. Provavelmente, o mais importante será a dificuldade em assegurar, no domicílio, as condições necessárias ao correcto tratamento da patologia em causa, como resultado das deficientes condições da habitação, da necessidade das mães manterem os seus horários de trabalho habituais (permanecendo a criança sozinha ou entregue a outros menores) e da dificuldade dos cuidadores compreenderem as instruções que lhes são transmitidas. Por outro lado, no momento em que recorrem ao serviço de urgência a situação clínica reveste-se sempre de maior gravidade. Os factores que concorrem para tal estão indicados no Quadro III. ${ }^{5}$

No que se refere às doenças infecto-contagiosas ou parasitárias, elas decorrem, na maioria das vezes, das deficientes condições de habitabilidade das residências, onde as condições de higiene não são muito fomentadas nem muito exequíveis (dada a promiscuidade e o sobrepovoamento dos espaços exíguos de que dispõem para morar), e da permanência destas crianças nos espaços exteriores, durante longos períodos do dia (por vezes sob condições meteorológicas adversas), em virtude da ausência prolongada, por motivos laborais, dos seus progenitores, principal razão, também, para a ocorrência mais frequente de acidentes domésticos nestas comunidades. ${ }^{5}$

Quanto à alimentação verifica-se que, em alguns casos, existe uma insuficiente ingestão alimentar no geral, mas sobretudo proteica, em consequência dos 
QUADRO III. Factores agravantes da situação clínica das crianças imigrantes quando doentes em contexto de urgência

- Situação socioeconómica desfavorecida do agregado familiar

- Indisponibilidade dos adultos para acompanhar, ou não valorização dos cuidados preventivos a prestar à criança (vacinação, consulta de vigilância de saúde)

- Não reconhecimento da gravidade da situação ou indisponibilidade dos adultos para procurarem cuidados curativos em fase precoce de doença

- Incumprimento/cumprimento parcial de terapêutica instituída anteriormente

- Incapacidade para ler/compreender instruções fornecidas em língua portuguesa

constrangimentos económicos da família, enquanto noutros se constata uma alimentação desequilibrada, muito rica em snacks açucarados e com alto teor de gordura, porque as mães estão ausentes durante todo o dia e não dispõem de outro alimento para deixar às crianças. Esta alimentação deficiente vai condicionar défices nutricionais, que conduzem a uma diminuição do estado imunológico das crianças, contribuindo para agravar o seu estado de saúde. A dispensa de refeições escolares, nestas situações, apenas permite uma resposta a curto prazo para problemas que são crónicos. ${ }^{5}$

Outro problema, a que é preciso estar atento, embora pouco frequente porque, geralmente, confinado a grupos africanos muçulmanos, é a prática da mutilação genital feminina. Esta prática cultural é atentatória da saúde e bem-estar físico e psicológico, pondo em risco a saúde sexual e reprodutiva das futuras mulheres, pelas alterações que determina no desejo e satisfação sexual e pelas complicações obstétricas e morte peri-natal. Não deve, contudo, ser dissociada do contexto cultural e ritual que a justifica, enquanto prática inerente à identidade de género, à condição de mulher e ao reconhecimento social, pois corre-se o risco de, devido à estigmatização social da comunidade que a pratica, esta passar a utilizar um maior secretismo na sua execução, podendo levar a problemas de saúde ainda mais graves. ${ }^{11,13}$

\section{Saúde do Adolescente}

Em relação aos jovens descendentes das comunidades imigrantes que já nasceram no país de acolhimento, o facto de serem colocados perante dois códigos de conduta, frequentemente contraditórios ou mesmo conflituosos (o que lhes é fornecido pela sociedade anfitriã, e a que eles se procuram adaptar, e o da sociedade de origem dos seus progenitores, com que são confrontados na vida familiar), pode levar ao aparecimento de efeitos desorganizadores sobre o seu comportamento, condicionando problemas psíquicos como: sentimentos de insegurança, perda de auto-estima e manifestações depressivas ou de ansiedade. ${ }^{9}$

Contudo, embora seja altamente provável a ocorrência desta patologia, ela não é, de todo, um fenómeno inevitável, dependendo dos vários factores em presença e do tipo de estratégia de adaptação que é adoptado a nível individual ou familiar. O que introduz, também, o conceito de resiliência individual e familiar, já que cada família é única no modo como desenvolve as suas estratégias de sobrevivência, na sua estrutura normativa e comportamental, na capacidade de resposta e de decisão de cada um dos seus elementos para resolver os problemas que o afecta e no tipo de interacções que estabelece com os outros subsistemas sociais. Estes diferentes comportamentos das famílias vão influenciar os percursos individuais dos seus elementos., ${ }^{2,9,14}$

Um factor que tem fortes repercussões na estabilidade e no bem-estar familiar é a alteração que se pode verificar nos papéis desempenhados, tradicionalmente, pelos vários elementos do agregado familiar, traduzida, não raramente, por uma inversão de papéis entre pais e filhos. ${ }^{10}$

Com efeito, se é frequente as crianças pequenas terem dificuldade na aprendizagem da língua do país de acolhimento, porque continuam a ouvir os seus familiares exprimirem-se na sua língua materna no domicílio, verifica-se, geralmente, o oposto nos jovens, em consequência da maior facilidade na aprendizagem da língua e da mais rápida adaptação ao novo meio social envolvente, fruto das interacções frequentes com jovens autóctones, na escola ou no local de habitação. As competências que desenvolvem permitem-lhes um controlo mais efectivo sobre este ambiente duplo, servindo, habitualmente, como intérpretes, ou ajudando os mais velhos nas formalidades burocráticas. Confe- 
rem-lhes, igualmente, aptidões que os tornam mais capazes para desempenhar certas funções, normalmente reservadas aos adultos da família, o que lhes proporciona uma falsa noção de independência e de desobrigação em relação ao cumprimento das regras de conduta vigentes na sua família. Como consequência, podem surgir graves problemas no seu relacionamento com os progenitores (sobretudo o pai) que, assim, vêem questionada a sua autoridade no ambiente familiar. ${ }^{5,9}$

Outra situação que ocorre nestas populações inseridas numa economia de mercado, em que a satisfação das necessidades através da aquisição de bens e serviços é assegurada pelo rendimento da família, é serem os jovens quem mais reage às campanhas publicitárias, que incitam ao consumo desenfreado, como marca de prestígio social e de sucesso. Em famílias caracterizadas pela pobreza e exclusão social, e marcadas por uma situação de grande disfuncionalidade e de enfraquecimento dos laços de solidariedade intrafamiliar, é habitual que cada um dos elementos tenda a procurar, individualmente, a resolução dos seus problemas. Confrontados com os fracos recursos económicos de que a família dispõe, e estimulados pelos ímpetos consumistas que lhes são incutidos pelo marketing agressivo, muitos enveredam por caminhos marginais, de delinquência e tráfico de droga, como forma de obterem os meios necessários para acederem ao que desejam. Outros desencadeiam perturbações mentais e comportamentos aditivos com recurso ao álcool ou a alucinogénios. $^{2,5,11}$

\section{Alteração dos papéis conjugais}

No percurso migratório pode ocorrer, igualmente, uma inversão de papéis entre os elementos do casal, resultante da valorização social da mulher imigrante neste novo ambiente, em relação ao marido/companheiro e ao padrão social de conduta que lhe era atribuído no seu país de origem. Apesar de, regra geral, possuir qualificação igual ou inferior à do marido/companheiro, o facto de ter um emprego remunerado permite-lhe experienciar a sensação de uma certa realização individual e alguma autonomia financeira, já que no seu local de origem estava, frequentemente, confinada à lide doméstica ou a trabalho em contexto familiar, não remunerado. ${ }^{5}$
Noutros casos, consegue arranjar trabalho antes e mesmo com remuneração superior à do marido. Aproveitando as actividades que lhes estão, tradicionalmente, reservadas pela sociedade de acolhimento - o trabalho doméstico que as introduz nos espaços domésticos das famílias autóctones (confrontando-as com outros tipos de relações e modos de vivência familiar) e o trabalho de limpeza, mais fragmentado no tempo e no espaço, que lhes proporciona um contacto mais estreito com a sociedade envolvente, estabelecem uma rede de relações sociais com pessoas de outra condição. Que serão utilizadas, no futuro, como relevante fonte de informação, sempre que necessitarem de aceder a certos bens ou serviços, ou quando for preciso ultrapassar algum obstáculo que se coloque a algum elemento do agregado familiar, o que as transforma em importantes mediadoras em relação a problemas inerentes ao seu estatuto sociocultural ou decorrentes da sua condição de imigrantes. ${ }^{5}$

Esta valorização da mulher pode ser vivenciada de forma pacífica, assente numa relação de respeito mútuo (porque longe dos constrangimentos impostos pelos usos e costumes do seu país natal), ou então induzir mudanças de comportamento no marido/companheiro, como consequência da perda das prerrogativas que detinha de acordo com as tradições do seu país de origem. Podem, assim, surgir situações de depressão e abuso de ingestão de álcool, que se acompanham, frequentemente, de comportamentos violentos e maus tratos sobre as mulheres, dando origem a situações potencialmente perigosas. ${ }^{2,5}$

Contudo, estas mulheres não pedem ajuda, não apresentam queixa por violência doméstica, nem se separam dos seus maridos, porque o seu estatuto legal, e o dos seus filhos, no país de acolhimento depende do elemento da família que solicitou a reunificação. Nestes casos, se ocorrer separação, divórcio ou repúdio pelo marido, são forçadas a regressar ao país de origem, ou a entrar em situação de estadia ilegal, se quiserem permanecer no país de acolhimento, acentuando ainda mais a sua situação de vulnerabilidade. ${ }^{2}$

\section{Saúde dos adultos}

Quanto ao estado de saúde dos adultos, verifica-se que, no momento da chegada ao país de acolhimento, detêm, geralmente, condições físicas e psíquicas superio- 
res à da população autóctone. Na opinião do Rui Marques, ex-presidente do ACIME, esta situação decorre da selecção natural que se faz sentir ao longo de todo o processo migratório, que só permite o êxito aos mais saudáveis e capazes de ultrapassar os obstáculos que se apresentam no seu trajecto. ${ }^{15}$

Porém, ao longo do tempo de permanência no país de acolhimento, vão sendo expostos a um conjunto de riscos superior ao dos nacionais, já que se ocupam em trabalhos mais desqualificados, mais sujos e perigosos e com horários violentos. Como consequência, os imigrantes apresentam índices elevados de doenças profissionais e de acidentes de trabalho (sobretudo na construção civil) que podem ser fatais, ou deixar o trabalhador em situação de grande vulnerabilidade, por não poder trabalhar nem ter acesso a prestações sociais que o apoiem nesse período, caso esteja em posição irregular. $^{2}$

Outra situação frequente diz respeito às condições de vida de alguns imigrantes, que se encontram a residir sozinhos no país. Com o intuito de enviarem o máximo de dinheiro possível para os familiares que ficaram no país de origem, despendem o mínimo com as suas necessidades, num enorme esforço de poupança, o que se traduz em alimentação deficiente. Porque também não existe alojamento de qualidade a preços acessíveis, sujeitam-se a residir em quartos de pensão sobrelotados, em condições promíscuas e pouco higiénicas, favorecendo o aparecimento de doenças. ${ }^{15}$

Estes constituem, por regra, o primeiro local no "percurso residencial” dos imigrantes, já que, de início, procuram apenas uma habitação para utilização temporária: quarto de pensão, alojamentos pertencentes aos patrões ou alugados em comum com familiares, compatriotas ou colegas de trabalho. Só procuram habitação mais condigna quando se procede à reunificação familiar, numa sequência de prioridades bem estabelecida: mais privacidade, mais espaço, melhor estado de habitabilidade e melhor localização. ${ }^{2}$

Como o corpo é utilizado como a principal ferramenta de trabalho, estar doente corresponde a não poder ir trabalhar, correndo o risco de poder ser despedido. Assim, muitos destes migrantes, sobretudo os que se encontram em situação irregular ou em maior precaridade laboral, não se permitem faltar ao trabalho para ir a uma consulta, pelo medo de perderem o em- prego. Muitos também não dispõem de recursos económicos que lhes permitam custear, por meios próprios, certas despesas de saúde: consultas ou exames de diagnóstico. Desta forma, vão relegando a sua saúde para segundo plano, até já não poderem aguentar mais, pelo que apenas procuram os cuidados de saúde em situações de urgência, em ambiente hospitalar. ${ }^{11,13,15}$

Outros problemas importantes com que se confrontam os imigrantes europeus extra-comunitários, na quinta e sexta década de vida, são a alta incidência de neoplasias, de doenças cardiovasculares e de doenças respiratórias crónicas, devido às condições ambientais a que estiveram longamente expostos nos seus países de origem e a estilos de vida não saudáveis: malnutrição, ingestão excessiva de álcool e tabagismo acentuado. Com efeito, embora dispusessem, nos seus países de origem, de uma cobertura de saúde gratuita e generalizada a toda a população, até recentemente não era dado o realce devido a acções de prevenção, nem de promoção de estilos de vida saudável ou de comportamentos de vigilância de saúde..$^{2,6,11}$

De igual modo, a ausência da família, e a separação do seu contexto sociocultural natal, podem conduzir a comportamentos desviantes, tanto a nível sexual (o que os torna mais propensos a sofrer de infecções sexualmente transmitidas) como a problemas do foro psíquico ou ao alcoolismo. ${ }^{1,11,15}$

Entre as infecções sexualmente transmitidas que afectam a população imigrante, a infecção por HIV tem incidência significativa e ocorre, maioritariamente, nas populações de origem africana, por transmissão sexual através do recurso à prostituição ou via endovenosa por consumo de drogas. Nestes casos verifica-se, também, uma alta incidência de tuberculose e hepatites. ${ }^{1,2,11}$

Quanto aos problemas do foro psíquico, em especial a depressão, constata-se que são frequentes, sobretudo nos primeiros anos de permanência no país, enquanto os indivíduos se encontram sozinhos, acompanhando-se, geralmente, pelo abuso da ingestão de álcool. Alguns casos evoluem mesmo para situações de incapacidade laboral total, com a consequente perda do emprego e de salário, e incapacidade ou vergonha de regressarem ao país de origem, o que os conduz à condição de "sem abrigo" nos espaços urbanos. Este modo de vida, caracterizado pela ausência de condições mínimas de habitabilidade, falta de cuidados básicos de 
higiene, má nutrição e manutenção do excesso de ingestão alcoólica, vai condicionar o aparecimento de problemas graves de saúde. ${ }^{2,11}$

Em algumas situações, observadas transversalmente entre imigrantes de todas as origens, depressão e alcoolismo estão associados à violência doméstica. $\mathrm{Na}$ maioria das vezes, as mulheres maltratadas permanecem com os seus maridos/parceiros, pelas razões apresentadas anteriormente, embora existam casos documentados de tentativa de suicídio, por dificuldade em continuar a suportar estes comportamentos. ${ }^{2}$

Quanto às situações de violência intra-comunitária, de que podem resultar ferimentos graves ou mesmo a morte, parecem estar associadas a confrontos entre grupos do crime organizado pelo controlo do território ou de certos tipos de tráfico, e afectam, sobretudo, as comunidades de europeus de Leste ou os chineses. ${ }^{2}$

No que se refere ao tráfico de mulheres, para trabalho de alterne ou prostituição, é um fenómeno que tem vindo a crescer em Portugal, envolvendo mulheres com idades, preferencialmente, entre os vinte e os trinta anos. Ao longo do trajecto migratório, desde o país de origem até ao seu destino, estas mulheres são sucessivamente violadas (para treino e experimentação) e depois revendidas, várias vezes, até serem colocadas nos estabelecimentos em que vão ficar a trabalhar. ${ }^{16}$

Algumas são angariadas mediante indução em erro, como promessas de trabalho na restauração ou hotelaria, ou recorrendo ao rapto e ameaça física, quer à própria mulher, quer à respectiva família. No entanto, outras vêm por vontade própria, até porque já estavam inseridas nos circuitos de prostituição nos seus países de origem. Outras, ainda, chegam sozinhas e, já em território português, contactam directamente os locais de alterne com o intuito que lhes seja facultado trabalhar nesses estabelecimentos. Isto porque se encontram desesperadas, sem conseguirem arranjar outro trabalho, ou quando pretendem ganhar a maior quantidade de dinheiro possível no menor período de tempo, para depois retornarem ao país de origem onde poderão fazer uma «vida limpa». Porém, também estas acabam por ser vitimizadas, porque não esperavam tanta violência e exploração por parte dos traficantes. No que se refere à prostituição mais recente, com origem na África subsaariana, é a própria família que vende as raparigas a uma rede de traficantes, pelo que desde logo sabem o destino que lhes está reservado. ${ }^{16}$

As práticas de coacção sobre as mulheres, com o intuito de as manter dependentes e submissas, comportam, para além da retenção dos seus documentos, as ofensas à sua integridade física e ameaças de morte, bem como ameaças de prática de actos violentos contra familiares no seu país de origem. Noutros casos, a sujeição e dependência são conseguidas recorrendo a práticas de feitiçaria (vodoo) num processo de intimidação e pressão psicológica. Vivendo num ambiente de medo permanente, estão, ainda, sujeitas à pressão de conservarem o seu aspecto exterior (beleza e equilíbrio psicológico) o melhor possível, de forma a poderem manter-se a trabalhar em ambientes mais seleccionados, onde a clientela é mais educada e respeitadora. Se perderem valor, são relegadas para locais mais degradados, onde ganham menos e são sujeitas a práticas sexuais mais aviltantes. ${ }^{16}$

Sob estas ameaças, as mulheres exercem as suas actividades em horários e condições violentas e mesmo quando portadoras de doenças infecciosas, ou outros problemas do foro ginecológico. ${ }^{16}$

É sobre as mulheres europeias e africanas subsaarianas que parece haver níveis de controlo e violência mais elevados, em oposição às brasileiras, onde o grau de coacção aparenta ser menor. ${ }^{16}$

\section{Saúde dos idosos}

No que respeita à população mais idosa, como consequência do reagrupamento familiar e da longa permanência de algumas comunidades imigrantes em Portugal, o país vê-se, actualmente, confrontado com a presença de um número significativo de estrangeiros de idade avançada, portadores de doença crónica e degenerativa e com graus de incapacidade física semelhantes, ou mesmo superiores (devido ao tipo de profissão que exerceram), aos da população autóctone. A esta situação não é alheio o facto de doentes e/ou familiares idosos de imigrantes se deslocarem, definitiva ou transitoriamente, para território português, para beneficiarem de cuidados sociais e/ou de saúde, na área da prevenção, ou para acederem a cuidados curativos, inexistentes ou menos diferenciados nos seus países de origem. Outros chegam, também, ao abrigo de acordos e convenções bilaterais, em matéria de saúde, celebrados entre o Estado português e os seus países de ori- 
gem, alojando-se em casa de familiares. Assim, tornam-se utilizadores regulares, ou potenciais, dos cuidados dispensados pelo Sistema Nacional de Saúde Português. ${ }^{5}$

Frequentemente estes idosos permanecem sozinhos a maior parte do dia, apresentando, muitas vezes, graves carências alimentares e não dispondo do acompanhamento necessário. Na sua maioria são de origem africana ou asiática, provenientes das antigas colónias portuguesas. Muitos não falam português, o que constitui mais um obstáculo a uma clara e eficaz comunicação interpessoal, para além das dificuldades decorrentes da diversidade cultural e étnica, particularmente marcadas nestas populações mais idosas, que só recentemente chegaram a Portugal. ${ }^{5}$

Nestes indivíduos é importante compreender a importância das práticas tradicionais, a que recorreram durante toda a vida, e dos curandeiros que consultam. Estes, profundamente conhecedores do uso das plantas para fins terapêuticos, são, frequentemente, considerados pelas suas comunidades, no país de origem, como os únicos detentores do poder de cura. ${ }^{2,5,11}$

Como tal, desconfiam da competência dos profissionais de saúde e estranham os métodos utilizados pela medicina ocidental, para além de que os tabus com o seu próprio corpo os impede de efectuar certos procedimentos técnicos, porque são considerados invasivos da sua intimidade. ${ }^{4}$

Finalmente, resta salientar a escassa investigação, realizada em Portugal, sobre problemas de saúde e utilização de serviços de saúde nos imigrantes de origem oriental, sobretudo nos que chegaram mais recentemente ao país: indianos, paquistaneses e chineses, presumindo-se que recorram, frequentemente, a terapias orientais. ${ }^{2,11}$

Para além disso, acresce, ainda, mencionar a falta de conhecimentos, por parte de alguns profissionais de saúde, sobre certas doenças que são raras nos países de acolhimento e, como tal, difíceis de diagnosticar, o que pode conduzir a situações potencialmente graves se não forem atempadamente reconhecidas. ${ }^{17}$

\section{CONCLUSÃO}

Em conclusão, importa compreender que os ganhos em saúde dependem, fortemente, de políticas sociais adequadas, pelo que a solução para a maioria dos pro- blemas expostos anteriormente passa, em primeiro lugar, pela implementação de medidas que promovam a inclusão social. Com base em parcerias entre o governo e organizações na comunidade, deverão desenvolver-se estratégias preventivas e de efectiva integração, de forma a combater a estigmatização, discriminação e vulnerabilidade associadas a estas populações. ${ }^{5,11,17}$

É urgente, e necessário, melhorar o acesso aos cuidados de saúde para todos os indivíduos, independentemente do seu estado legal. De igual modo, uma maior participação de pessoas de diferentes origens étnicas nos serviços de saúde poderia contribuir para prevenir a discriminação e facilitar a utilização dos mesmos.,17

Deve ser dada, também, especial atenção às acções de educação para a saúde, direccionadas para a prevenção, de modo a mudar atitudes e comportamentos de risco, promovendo hábitos de vida saudável, com um enfoque especial na população mais jovem. ${ }^{11}$

Por fim, porque o desconhecimento dos aspectos culturais destes imigrantes, em conjunto com as representações estereotipadas que lhe estão associadas, conduz a atitudes e comportamentos desadequados por parte dos prestadores de cuidados de saúde, traduzidos num relacionamento difícil, torna-se necessário implementar a formação e educação dos prestadores dos cuidados de saúde na área da multiculturalidade, dando-lhes a conhecer a importância que os aspectos culturais têm nas atitudes e comportamentos dos indivíduos em situação de saúde ou de doença., ${ }^{5,18}$

\section{REFERÊNCIAS BIBLIOGRÁFICAS}

1. Saúde e migrações na UE [online]. 2007. Disponível em: http:// www.portaldasaude.pt/portal/conteudos/a+saude+em+portugal/presidencia+ue/documentacao/conclusoes+conf+saude+ue.htm [acedido em 06/11/2008].

2. Fonseca ML, Ormond M, Malheiros J, Patrício M, Martins F. Reunificação familiar e imigração em Portugal: relatório final. Lisboa: Alto Comissariado para a Imigração e Minorias Étnicas; 2005.

3. Péchevis M. Les enfants de migrants. In: Lebovici IS, Diatrkine R, Soulé M. Nouveau Traité de Psychiatrie de l'Enfant et de l'Adolescent. Paris: PUF; 1995. p. 2287-301.

4. Ramos MN. Comunicação e saúde em contexto multicultural. In: Actas IV Encontro de Estudos Multidisciplinares em Cultura; 2008 Maio 28-30; Bahia, Brasil; 2008. Disponível em: http://www.projetoradix.com.br/arq_artigo/textos/14556-02.pdf [acedido em 06/11/2008].

5. Soares P. A promoção de saúde na infância em contexto multicultural [dissertação]. Lisboa: Universidade Aberta; 2003

6. Monteiro AP. Imigração e Saúde - imigrantes da Europa de Leste em Portugal [online]. 2006. Disponível em: URL:http://www.esenfc.pt/es- 
enfc/admin/conteudos/downloadArtigo.php?id_ficheiro=219\&codigo $=$ [acedido em 06/11/2008].

7. Rocha-Trindade MB. Sociologia das Imigrações. Lisboa: Universidade Aberta; 1995.

8. Ramos N. Educação precoce e práticas de cuidados infantis em meio urbano. In: Actas do Colóquio Viver (n)a Cidade. Lisboa: [s.r.]; 1990. p. 315-23.

9. Ramos N. Maternage en milieu portugais autochtone et immigré: un étude ethnopsychologique [dissertação]. Paris:Université René Descartes (Paris V); 1993.

10. Ferro-Bucher J. Migration familiale, identité et changement socio-culturel. In: Lavalle M. Identité, culture et changement social. Paris: L'Harmattan; 1990. p. 45-52.

11. Santinho MC. Os determinantes socioculturais da saúde e os contextos específicos da pobreza, minorias étnicas e imigrantes. Revista Lusófona de Ciências e Tecnologias da Saúde 2005; (2) 2:73-7.

12. Laulun Y-M. L'Europe malthusienne. Géopolitique: Revue de l'Institute International de Géopolitique 2001; 74: 9-18.

13. Frade A, coord. Por nascer mulher...um outro lado dos Direitos Humanos. Lisboa: Associação para o Planeamento da Família; 2007.

14. Berry J. Acculturation et adaptation psychologique. In: Retschizky I, coord.. La Recherche interculturelle. Vol. 2. Paris: L'Harmattan; 1989. p.135-45.
15. Médicos do Mundo [revista online] 2006 Jun. Disponível em: http://www.medicosdomundo.pt/content/boletins/boletim16junho2006.pdf [acedido em 06/11/2008].

16. Peixoto J, Soares AG, Costa PM, Murteira S, Pereira S, Sabino C. O tráfico de migrantes em Portugal: perspectivas sociológicas, jurídicas e políticas. Lisboa: Alto Comissariado para a Imigração e Minorias Étnicas; 2005.

17. Weekers J [entrevista]. 2008 Julho. Interface Saúde. Disponível em: http://www.algebrica.pt/Arquivo/Newsletters/esaude/60/index.htm [acedido em 06/1/2008].

18. Rosenberg E, Richard C, Lussier MT, Abdool SN. Intercultural communication competence in family medicine: lessons from the field. Patient Education and Counseling 2006 May; 61 (2): 236-45.

\author{
ENDEREÇO PARA CORRESPONDÊNCIA \\ Paulo Estrela \\ Rua Alexandre Ferreira $n^{\circ} 30,7^{\circ}$ Dto \\ 1750-011 Lisboa \\ Telef: 217575816 \\ E-mail: pauloestrela@ sapo.pt
}

Recebido em 20/01/09

Aceite para publicação em 05/02/09

\section{ABSTRACT}

Objective: The purpose of this article is to present the major health problems of cultural diverse populations in Portugal, immigrant workers and their families, in the context of providing health services.

Methods: A literature review was made, using relevant literature and online database, combined with the own researches, concerning health problems of immigrants, and their access to and their consumption of health care. Searches were limited to English, French, Spanish and Portuguese language-published research in the last eight years.

Conclusions: Evidence shows that immigrants often experience many difficulties in accessing and using available health services, what makes them a group of health risk. Evidence also demonstrates that health problems, in immigrants, are the consequence of many different conditions: physical, psychological and, perhaps, above all, social conditions, which increase the risk of becoming ill. Care of immigrants involves not only, reducing risk and treating illness, but also providing social support to both patients and their families, in order to effectively reduce health disparities. So, the best approach would be the combination of measures that could, not only, reduce the consequences of the social stigmatization and exclusion of these population, providing information about their cultural characteristics, beliefs and values, but also implementing early identification and treatment of their health problems and promoting patient education, through programs that stimulate an healthier life style, especially in younger people. In the same way, to bridge the language barrier, the use of interpreters, or cultural mediators, appears to be important in promoting an effective doctor-patient communication and relationship. Finally, because health professionals still lack adequate knowledge of the cultural patterns and specific needs of this population, family physicians should undergo a specific training program to become aware of the relevance of patient's different cultural background, to overcome stereotypes and to acquire information and competences on intercultural communication, to improve the quality of care of this population.

Keywords: Immigrants; Health Care; Health Problems. 